\title{
The Future of Rehabilitation in Psychiatry
}

\author{
John Reed, Community Psychiatry Research Unit, Hackney Hospital, London
}

A meeting of psychiatrists with an interest in rehabilitation was held in Oxford in April 1983 just prior to the College Quarterly meeting. The meeting was convened by Dr Brenda Morris and chaired by Professor John Wing; its purpose was to discuss the scope and future direction of rehabilitation in mental illness.

Professor Wing, opening the meeting, paid tribute to the work of Dr Freudenberg who had recently died. He then referred to the DHSS's long-term policy: to provide district based psychiatric services and run down the large menta illness hospitals with eventual closure, except where they could form part of a single district service.

The number of mental illness hospital beds had fallen by more than half since the peak in 1954, but there was still considerable discussion about the size and nature of the problem posed by patients who become chronically ill and disabled. The concept of rehabilitation had originally arisen from concern about neglect of the 'old long-stay' patient. In addition, the problem of the actual or potential neglect of new chronically disabled patients, whether in hospital or outside, had to be faced. Were the skills developed for the old long-stay equally relevant to these new problems? Many mentally disabled people were now living precariously outside hospital, at times in unsatisfactory accommodation and with no realistic possibility of getting a job. What new skills and services were necessary to ensure a decent quality of life for these patients?

Professor Wing thought that there was a danger that the term 'rehabilitation' might imply strictly short-term methods of care. But if this definition applies and recovery was not achieved there would be a sense of failure, felt both by patients and staff. A broader concept would be "long-term community management': perhaps the term 'rehabilitation' was too uncertain in meaning and had too many outdated connotations. Certainly rehabilitation in terms of enabling long-stay patients to develop skills needed to live outside hospital was now only a small part of the work involved. Whatever the term used, the rehabilitation consultant needed to be concerned with continuity of patient care, coordination of health, social and voluntary services and overall planning for the development of district services for chronically mentally disabled people.

Dr Brenda Morris presented a paper based on her survey of consultants with an interest in, and a responsibility for, rehabilitation. The survey was still incomplete but so far information had been collected on 56 consultant posts with a special interest in rehabilitation. The degree of commitment varied from one session per week to full-time. The responsibilities ranged from clinical responsibility for 250 long-stay beds to membership of the Joint Health Care Planning Group. Facilities and resources also varied widely-34 reported a variety of residential care facilities in the community, such as group homes, hostels, lodgings, etc.; 35 hospitals had a rehabilitation team and/or rehabilitation committee; 33 rehabilitation consultants had some involvement with OT and IT departments and 35 were involved with day units. Fewer (27) were associated with work rehabilitation or sheltered work settings in the community. Thirty-two mentioned liaison with social services and/or voluntary organizations. Twenty-nine had one or more juniors who were participating in a training rotation, but most junior psychiatrists worked only part-time in rehabilitation. Only six senior registrar posts with any serious commitment to rehabilitation came to light (Morpeth, The Maudsley, Southampton, Claybury, Springfield and St James', Portsmouth)

Most rehabilitation consultants attach considerable importance to their teaching role, giving lectures to membership trainees, nurses, social workers, medical students and others. Nine reported holding regular seminars.

When completed, this survey will form the basis of a directory listing rehabilitation facilities in the United Kingdom and will be made available through the College.

General impressions gained from the survey were that the most widely and coherently developed services were found where a specific consultant had responsibility for the development of the service. The services appeared most effective when organized for an entire health district and not just for a single hospital. Rehabilitation was seen as a team operation involving both statutory and voluntary services, and housing as well as health and personal social services. It was a long-term process with no clearly defined end.

The meeting then divided into working groups to consider different aspects of rehabilitation.

What does the work of a consultant in rehabilitation involve? This group addressed itself to two apects of rehabilitation mentioned by Professor Wing. Was rehabilitation (i) a specific well-defined programme for the achievement of short-term goal-oriented tasks, or (ii) the provision of lifelong support of the chronically disabled so that they might use their strengths to greatest advantage and be handicapped as little as possible?

The second definition of the work of a consultant in rehabilitation was felt to be more appropriate since it included the first definition, but extended beyond it in important ways. The work of such a consultant is not just hospital based but involves planning and working across a health district. The hospital should be considered to be part of the community as one element of a comprehensive service, and not as a separate entity. The consultant should be responsible for ensuring the availability of services for the 
optimum care of the chronically disabled, regardless of whether the patient is living in the hospital or outside. It was felt that a 'Continuing Community Care' team should be available to each district. General psychiatric consultants should generally retain responsibility for chronically ill patients. They would find the special skills developed when dealing with the chronically ill of wider therapeutic use. In order to avoid the neglect that might be associated with such a system, the Continuing Community Care team would provide an advice and resource centre to help plan the future care of any chronically ill patient referred. All patients at high risk should be known to the CCC team. Sufficient flexibility of staff would be needed to enable the CCC team to give additional therapeutic input at times of change or crisis for a patient. In this way the rehabilitation consultant would have a satisfying clinical job and be involved with broader social and managerial aspects of district care.

\section{Resources needed by a consultant in rehabilitation}

These resources were not easily enumerated since they would vary from one district to another depending on demographic and social characteristics. One necessity was a clear commitment by the district health authority to the development of a service for chronically ill patients both in hospital and in the community: in other words that the district would stand by DHSS policy on priorities. A similar commitment was also necessary from other consultant colleagues in the district. The major resource initially would be the time and staff necessary to assess the needs of the district in terms of the provision of a diversity of accommodation, occupation, and social activities for the chronically psychiatrically disabled people of the district. Following this assessment of need an effective mental health care strategy group with representatives from health, social services, housing in the voluntary sector and an effective Joint Health Care Planning Team was vital in delivering the facilities planned.

An important role for a new 'rehabilitation consultant' was to plan and develop such schemes. Most medical and psychiatric training was of little help in this work, but some districts had made very satisfactory progress with development work being done jointly by a consultant and a full-time non-medical worker with experience in another area such as social research and planning, housing, etc. Provided both medical and non-medical planners were agreed that the need was to develop a balanced service, the frequently feared battles with 'anti-psychiatry' do not materialize. Two major requirements in planning and developing services are time and knowledge of the 'market areas' involved, such as housing, voluntary agencies, funding, running charities, etc. Although few consultants have the time or the expertise for this work, it is essential that at least one in each district should be able to play a part in it.

The need for each district to have an effective data base, possibly a computer based service register, was emphasized. Districts were so varied in social structure that only locally based research could give a clear picture of local needs. It was essential to assess the diverse needs of the patients.

\section{Training in rehabilitation}

Some training in rehabilitation was part of general psychiatric training. All trainees should be made aware of the longer term consequences and social implications in mental illness and should know the basic techniques used to help patients to adjust to disabilities. Some knowledge of the techniques of assessment of the assets and the disabilities of the patients was also important as part of the general training. This training should not only take place within the confines of a hospital, but should include visits to local residential and occupational facilities. More extensive training should be available at senior registrar level. A most important aspect of clinical training is developing a knowledge of the organization of the health services, social services, housing and the voluntary sector, how to plan developments and how to implement the plan, sources of funding and how to apply them, how to work in committees or, even better, how to get committees to work for you. A knowledge of relevant research was an advantage when assessing the needs of a district. The need for training other professional groups in skills relevant to care for patients outside hospital prior to a move towards district based services was emphasized. Training secondments to 'model' districts should be encouraged as should proleptic consultant appointments.

\section{Conclusion}

Summing up, Professor Wing emphasized the necessity for someone speaking for the needs of psychiatry as a whole in each district and the needs of the chronically psychiatrically disabled in particular as they were still rarely getting a fair share of resources in terms of money, time and staff. One senior psychiatrist in each district should take special responsibility as the leader and developer of better services for these groups, both by clinical example and by occupying a strategic position in the organization of the planning process. Whether this post was designated as 'rehabilitation' consultant or 'consultant with responsibility for hospital/community liaison and planning' was less important than ensuring that the post carried sufficient power to enable a full range of services for the chronically disabled to be provided locally.

There was general agreement on the need for further opportunities for discussion and a small group, consisting of Professor John Wing, Dr Brenda Morris, Dr John Howat and Dr John Reed, was asked to organize a further meeting. There was also agreement that regional groups bringing together professionals working with the chronically psychiatrically disabled should be encouraged. 